\title{
MACHADO TRADUTOR DE ASSIS: A CONSTRUÇÃO DA IDENTIDADE DE TRADUTOR NO SÉCULO XIX
}

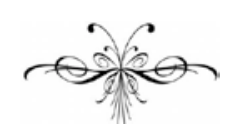

\section{LOURDES SETTE}

Resumo: Este artigo tem como objetivo definir, com base em sua prática e posicionamento teórico como tradutor, o tipo de identidade profissional que Machado de Assis construiu no século XIX para si mesmo e para seus colegas de ofício. A referência teórica sobre identidade adotada neste trabalho se alinha com as ideias pós-modernas sobre tradução e identidade, sobretudo as dos estudos culturais e da psicanálise.

Palavras-chave: Machado de Assis; tradutor; identidade; estudos culturais; psicanálise.

\begin{abstract}
This article aims to define, based on his practice and theoretical position as a translator, the type of professional identity Machado de Assis constructed in the nineteenth century for himself as well for his colleagues. The theory of identity used in this work encompasses postmodern ideas about translation and identity, especially those derived from Cultural Studies and Psychoanalysis.
\end{abstract}

Keywords: Machado de Assis; translator; identity; Cultural Studies; Psychoanalysis.

\section{Os estudos sobre Machado de Assis}

$\mathrm{M}$ uito se tem estudado o escritor Machado de Assis; no entanto, não encontramos, nem de perto, a mesma quantidade de estudos sobre o tradutor Machado de Assis. De acordo com Pinto do Carmo (1953), Lêdo Ivo (1976) (apud FERREIRA, 2003, p. 22) e Duarte (2008), embora o percurso literário desse importante autor brasileiro tenha sido pautado pela prática tradutória e, consequentemente, pela reflexão sobre ela, a historiografia literária brasileira ainda não deu o destaque devido ao papel desse ofício na carreira do Bruxo do Cosme Velho. O mesmo acontece no campo dos Estudos da Tradução. 
A historiografia da tradução brasileira menciona Machado como tradutor de peças teatrais e folhetins franceses no século XIX (WYLER, 2003, pp. 92-3). Há também trabalhos relevantes sobre Machado de Assis traduzido (GLEDSON, 1998; e CUNHA, 2011;) e sobre Machado de Assis traduzindo (GALANTE DE SOUSA, 1955; MAGALHÃES JÚNIOR, 1981; MASSA, 2009; FERREIRA, 2004; BARRETTO, 2007; FARIA, 2010; e BONACIN e SCHÄFFEL, 2010).

No entanto, sua atuação como tradutor e teórico da tradução, que se estende desde o início de sua carreira como escritor até a maturidade, ainda carece de ser estudada com uma abrangência que faça jus à importância de sua contribuição para a cultura nacional e à sua produtividade prática e teórica como tradutor. De acordo com Massa (2008, p.11), o ofício de tradutor exercido por Machado de Assis é "um aspecto praticamente ignorado de sua atividade literária.”

Essa afirmação é ratificada por Ferreira (2003, p. 23). Segundo a autora, o trabalho de pesquisa de Jean-Michel Massa (idem) não foi retomado por "nenhum estudioso brasileiro". De fato, é bastante curioso que, até hoje, um pesquisador francês ainda seja considerado quem mais conhece o tradutor Machado de Assis. Entretanto, não serei eu, uma pesquisadora brasileira, a realizar, neste contexto limitado, a tarefa hercúlea de superar o trabalho de fôlego realizado por Massa. Pretendo, no entanto, lançar alguma luz sobre um aspecto ainda não explorado de um dos maiores escritores da língua portuguesa, sua identidade de tradutor, e assim diminuir um pouco a carência de produções escritas sobre o assunto.

\section{A tradução no Brasil na época de Machado de Assis}

Lia Wyler, em sua história da tradução no Brasil, destaca o romance-folhetim e o teatro como os fios condutores do romance popular europeu que levaram ao surgimento de nossa novela televisiva e, sobretudo, ao desenvolvimento da tradução no século XIX em nosso país (2003, p. 91).

Esses gêneros literários eram traduzidos de várias línguas, como o francês, o inglês, o italiano e o alemão. A demanda por romances-folhetim era tão grande que um dos jornais que os publicava na época, o Jornal do Comércio, o fazia "quase ao mesmo tempo em que eram divulgados em Paris” (idem, p. 92). As traduções de peças teatrais também proliferaram, uma vez que as produções em língua portuguesa não conseguiam saciar a fome de cultura da população do Rio de Janeiro e das províncias. Esses tipos de tradução também eram muito populares porque ocupavam, de certa forma, o espaço deixado pelo entrave da produção de livros nacionais e traduzidos no século XIX (Ibidem, p. 107).

Apesar de lamentar que as cenas teatrais brasileiras tenham sido alimentadas por traduções, as quais, em vez de estimularem o poeta dramático, fizeram surgir, em seu lugar, o tradutor dramático (Ibidem, p. 100), Machado e suas traduções contribuíram diretamente para a construção de um teatro nacional (GALANTE E SOUSA, apud WYLER, ibidem) e, indiretamente, para a construção da identidade cultural brasileira e, também, afirmo, para a construção da identidade do tradutor brasileiro no século XIX. 


\section{A tradução na vida de Machado de Assis}

Machado começou a traduzir em 1857, com apenas 18 anos, e continuou até 1894 (MASSA, 2008, p.19). Tendo morrido em 1908, pode-se dizer que as traduções o acompanharam por toda sua vida ativa.

Os principais gêneros literários que traduziu foram o teatro, o ensaio literário e histórico, a poesia e o conto, remontando a um total de 46 textos. Entre os autores traduzidos estavam Shakespeare, Balzac, Alexandre Dumas, Lamartine, Schiller, La Fontaine, Victor Hugo, Edgar Allan Poe, sendo os idiomas dos originais o inglês, o alemão, o espanhol, o francês e o italiano. Pelas análises realizadas por Massa (idem, p. 37, 45), há dúvidas quanto ao domínio dessas línguas por parte de Machado, uma vez que, em vários trabalhos, observam-se falhas de compreensão que apontam para a falta de um conhecimento adequado delas.

Com relação à importância que a tradução teve na vida de Machado de Assis, segundo Massa (idem, p. 28), ela não desempenhou "um papel essencial na atividade literária do jovem escritor", tendo sido um mero "passatempo". No entanto, essa não é a opinião de Ferreira (2003, pp. 23-4) que afirma que a atividade tradutória foi relevante na carreira literária do Bruxo do Cosme Velho. A visão da pesquisadora me parece mais acurada não apenas por Machado ter passado seus anos produtivos traduzindo, mas também, como já estudado, pela influência que as traduções tiveram em suas obras autorais, servindo mesmo "como alimento para seus pensamentos" (idem, 2003, p. 27). A relevância da tradução na vida de Machado é ainda mais reforçada se consideramos que seu primeiro livro publicado, Queda que as mulheres têm para os tolos (reedição: Crisálida, 2003), é uma tradução (MASSA, 2008, p. 62), tendo sido considerado, erroneamente, por muitos, como de sua autoria (FERREIRA, 2003, p. 24).

Um estudo comparativo entre trechos de originais e traduções feitas por Machado (MASSA, 2008) deixa dúvidas se o resultado de seu trabalho pode ser classificado, de fato, como tradução ou se seria, na verdade, uma adaptação, tantas foram as alterações e omissões encontradas. No entanto, qualquer que tenha sido sua intenção, traduzir ou adaptar, e apesar das falhas de interpretação apontadas por alguns críticos da época e de hoje (MASSA, 2008, p. 59), não há dúvida de que o escritor brasileiro, através de suas traduções, permitiu que seus compatriotas pudessem ter acesso à produção cultural de países distantes e aos gêneros literários que alimentaram a fome de cultura e a imaginação de seus leitores, contribuindo para enriquecer a literatura nacional e para construir a identidade de tradutor no século XIX.

\section{O estudo da identidade do tradutor}

Em minha dissertação de mestrado, pesquisei a identidade do tradutor literário na década de 1990 (SETTE, 2002). A pesquisa se baseou em depoimentos desse profissional sobre sua tarefa e seu status. Esses depoimentos foram extraídos de paratextos, entrevistas e artigos escritos por eles e me permitiram entender o tipo de identidade profissional que estava sendo construída naquela época.

Após analisar esses discursos, constatei que os tradutores literários utilizavam metáforas depreciativas para descrever seus sentimentos enquanto tradutor, e a seu ofício. De acordo com Susan-Bassnet, "as metáforas usadas por tradutores refletem seus pensamentos sobre o papel e o status da tradução em suas próprias 
épocas (1993, p. 46), e eu acrescentaria que elas também refletem o papel e o status do tradutor e, portanto, contribuem para a construção da identidade profissional.

A utilização de metáforas depreciativas reforça a baixa autoestima e a sensação de incapacidade do tradutor para exercer seu ofício, mantendo-o em uma atitude que Lages (1992) denominou de "melancólica” e que eu considerei, em meu estudo, como a identidade de tradutor predominante nos anos 1990.

Segundo os estudos culturais, "as identidades são pontos de apego temporário às posições-de-sujeito" — nas quais o indivíduo investe por se identificar com elas - , que são constituídas pelas práticas discursivas as quais, por sua vez, são estabelecidas pelos ideais culturais. No caso da tradução, esses ideais podem estar explícitos ou implícitos nos discursos dos próprios tradutores.

Ao se referirem, em suas práticas discursivas, a eles mesmos e ao trabalho que executam usando metáforas depreciativas, os tradutores constroem e reconstroem uma identidade profissional nesses moldes e, portanto, acabam formando uma imagem negativa que, por sua vez, provoca um sentimento de rejeição dessa identidade, fazendo com que o indivíduo volte seu olhar para outra identidade mais valorizada. No caso da tradução, a do autor do texto a ser traduzido.

Mas como se constrói uma identidade? Através do processo de “identificação". Para a psicanálise freudiana, a identificação é "um processo central pelo qual o sujeito se constitui e se transforma, assimilando ou se apropriando, em momento-chave de sua evolução, dos aspectos ou traços dos seres humanos que o cercam” (ROUDINESCO, 1998, p. 363). É na relação com o outro que o processo de identificação ocorre, dando origem à identidade, que é construída e reconstruída ao longo da vida de um indivíduo. Segundo a psicanálise, "a identificação indica não apenas a presença, mas também a efetividade do outro no sujeito e no corpo, de maneira que podemos dizer 'eu [ego] sou o outro'” (BIRMAN, 1997, p. 32).

O desejo de querer ser o outro, por exemplo, o autor do texto a ser traduzido, liga o tradutor ao autor porque traz consigo o desejo de se sentir igualmente valorizado, isto é, o tradutor deseja sentir, em alguma medida, que é prestigiado como um autor - considerado em nossa cultura como o senhor dos sentidos - , o que lhe permitiria deixar de se sentir inferior, como um escravo, por exemplo.

\section{Machado Tradutor de Assis: a identidade melancólica do Bruxo do Cosme Velho}

Em meio século de vida criativa, Machado de Assis assumiu identidades diferentes: a de jornalista, repórter, poeta, escritor, crítico literário e tradutor. A identidade de tradutor de Machado de Assis foi sendo construída na prática, mas também nas reflexões teóricas sobre tradução que revelou ao longo de sua vida. Segundo Ferreira (Ibidem, pp. 22, 27, 30), “a teoria de tradução de Machado de Assis está disseminada em sua obra”, tendo sido situada "próximo das teorias desenvolvidas nos Estudos da Tradução no século XX”, mais especificamente as que adotam “o entendimento 'pós-moderno' do processo tradutológico em que o tradutor adquire autonomia e cria um segundo original”.

Essa teoria pode ser encontrada em crônicas, críticas teatral e literária e paratextos (FERREIRA, 2003, p. 21) escritos por Machado ao exercer a atividade tradutória como uma prática textual. Ela também pode ser depreendida na análise de seu processo tradutório, porque, segundo Rosemary Arrojo (Ao pé da letra, s/d), 
é óbvio que todo tradutor que consiga publicar ou vender seu trabalho segue uma "ideologia”, uma "teoria” de tradução determinada, explícita ou implicitamente, pela comunidade que aceita e consome sua tradução. Ou seja, todo tradutor tem, obrigatoriamente, uma "teoria” de tradução, caso contrário não poderia traduzir. [...] Essa teoria já se encontra embutida na prática de todos os dias, por trás de cada decisão que o tradutor toma.

Com base no processo tradutório, nas escolhas feitas ou, em outras palavras, no modus operandi do Bruxo do Cosme Velho, Ferreira (idem, p. 21) o classifica como um tradutor stricto sensu pelo respeito que demonstrou pelo original ao se utilizar da equivalência lexical entre original e tradução. Essa opinião, contudo, não é compartilhada por outros estudiosos.

De acordo com Massa, o escritor brasileiro "enquanto tradutor, desejava difundir, numa esfera cultural que ele conhecia bem, um testemunho, um pensamento, ou mesmo uma mensagem que ele tirava das melhores fontes estrangeiras" (MASSA, 2008, p. 97) e o fazia escolhendo o texto a ser traduzido, sempre que este não lhe era imposto, por sua qualidade. Mas, em qualquer caso - escolhido ou imposto Machado, muitas vezes, deu ao texto de chegada seu toque pessoal, adicionando-lhe seu "molho", e utilizando-o como inspiração para a escrita de textos próprios. Assim, a meu ver, Machado conseguiu satisfazer seus anseios não apenas no nível social, mas também no individual se considerarmos que "traduzir é se educar e difundir um patrimônio cultural” (MASSA, 2008, p. 98).

A manipulação — no sentido dado ao termo por Theo Hermans - do original pelo tradutor Machado chegou a tal ponto que, ao compararmos texto de partida e de chegada, observamos que eles diferem tanto que, de acordo com Massa (2008, p. 17, 61,68), poderíamos hesitar em classificar sua leitura idiossincrática do texto de partida como "lapso, a falta por desatenção" e considerar o de chegada como “o desejo de se adaptar aos costumes brasileiros”, ou seja, naturalizar o texto estrangeiro. Poderíamos, então, nesse caso, optar por rebatizarmos o texto meta de recriação, ou de uma tradução que expressa a máxima de que "Traduzir não é igualar, mas superar o original” (MASSA, 2008, p. 98).

A ideia de superação do original, contudo, parece ter sido levada às últimas consequências por Machado tradutor ao ponto de estudiosos, como Massa e Maia Neto, considerarem que ele não foi apenas influenciado pelas traduções que fez de Shakespeare, mas que chegou mesmo a se apropriar delas e a transformá-las em textos próprios (apud FERREIRA, 2003, p. 27). É preciso esclarecer, no entanto, que o escritor brasileiro, ao agir dessa forma, não tomava posse indevida de propriedade intelectual alheia. Na época dele, ainda não havia a preocupação com a questão dos direitos autorais. Segundo Wyler (2003, p. 98), “os direitos de propriedade literária, científica e artística, somente seriam consolidados pelo Código Civil Brasileiro de 1916”, oito anos após sua morte.

Com relação à discussão sobre a fidelidade ao texto original, de acordo com Massa (2013),

no século XVIII e, provavelmente, no XIX, não havia ainda a consciência ou o consenso de que a tradução deveria ser o mais fiel possível ao original. Pelo contrário, o comum é que o tradutor tomasse muitas liberdades [...] em relação ao texto original. Muitas vezes, alterava tanto o original de um poema ou um trecho de prosa que acaba sentindo que fizera outro texto. 
O desenvolvimento dos Estudos da Tradução, a partir da década de 1970, intensificou os debates a respeito dos conceitos de original, autoria e fidelidade no campo da tradução.

Mais importante, em toda essa discussão sobre o processo tradutório e a (in)fidelidade de Machado de Assis, é que ela nos permite entender o tipo de identidade que ele construía para si próprio e para seus colegas de ofício no século XIX. Segundo Massa (2008, p. 99), ao traduzir, "Machado de Assis esquece a regra de ouro do tradutor - o dever da fidelidade - e faz ouvir sua voz", a qual parece não expressar sua identidade de tradutor, mas sim a de autor. A infidelidade do tradutor oitocentista é justificada pelo pesquisador francês, porque, no caso de Machado, “a tradução é o ato de um homem de letras cuja atividade criadora é tanto indiscutível como variada" e, por isso, "naturalmente a tradução tenderá a se afastar do modelo, quase que contra a vontade do escritor (Ibidem, p. 17)."

Vejo, entretanto, que, ao deixar aflorar sua identidade de autor em detrimento da de tradutor, Machado mantém a coerência entre ação e discurso. Ao expressar sua opinião sobre a conduta de seus companheiros de ofício, ele utilizou metáforas relativas à escravidão (apud FERREIRA, 2003, p. 28) por considerar que "a literatura brasileira e o teatro continuavam dependentes da cultura europeia, apesar da independência política”. Criticou a atitude servil dos tradutores diante do texto estrangeiro e denunciou "o nonsense de se traduzir mimeticamente sem refletir sobre o texto que estava sendo traduzido" (idem, pp. 22, 29), sobretudo na tradução de teatro por este ser uma arte que deveria "ser uma reprodução da vida social na esfera de sua localidade” (apud FERREIRA, Ibidem, p. 29), aproximando-se, assim da realidade brasileira.

Em outras palavras, o desejo de difundir cultura e de ser o mensageiro do estrangeiro, além da manipulação do texto original para transformá-lo em outro, deixam entrever seu desejo mais profundo de abandonar a identidade de tradutor, vista como passiva e servil, e assumir a de autor, produtor ativo de significados e veículo para a disseminação cultural.

Já sabemos que a relação do Bruxo do Cosme Velho com os textos de partida foi tudo, menos servil. Seu projeto tradutório rompe com a dicotomia original/tradução de tratar o segundo termo da equação como autônomo, retirando-o da periferia e alçando-o ao lugar de destaque que merece na literatura nacional.

Até parar de traduzir para assumir em tempo integral o papel de autor de suas obras, as duas identidades - a de autor e a de tradutor - coexistiram e se confundiram. A confusão fica evidente quando Massa afirma que, com suas traduções, "Machado de Assis nos diz que um tradutor não pode se furtar a ser um escritor, pois que ele mesmo é autor (Ibidem, p. 100).” Na conclusão de seu trabalho sobre Machado tradutor, o pesquisador francês nos lembra de que "Machado de Assis é um escritor; pode-se fingir esquecê-lo de uma hora para outra, mas o tradutor se encarrega de nos lembrar” (2008, p. 97).

E ele o faz, de fato, ao escrever no Prefácio da antologia poética de Raymundo Correa que um tradutor "perfez com o amor dos originais as traduções que apresenta”, apontando, assim, "para uma nova compreensão do tradutor como autor”, valorizando "o trabalho criativo e autônomo do tradutor, considerando-o autor de uma obra que adquire características particulares em relação ao texto primeiro (apud Barreto, 2007).” Machado levava tão a sério suas ideias sobre autoria quando fazia traduções que provocou a afirmação de Sérgio Bellei de que, ao se aproximar do texto 
de Poe, “The Raven”, Machado não estava traduzindo, mas fazendo outra coisa (BARRETTO, 2007), tal foi o afastamento do original que sua tradução revelou.

Foi somente a partir de 1870, com o "espaçamento das traduções", as quais passaram ao "segundo plano" (MASSA, idem, pp. 80, 13), que a identidade que desejava construir para si pode, enfim, ser plenamente assumida. Isso só foi possível porque "a suspensão das traduções marcaria talvez o momento em que o escritor considerou ter atingido sua plenitude literária”, alforriando-o para assumir a mais prestigiada delas, a de autor. E é essa identidade autoral que sobrepuja a de tradutor, o que foi extremamente importante para a literatura brasileira, mas que, a meu ver, não ajudou a construir a identidade do tradutor no século XIX.

\section{Concluindo}

A imagem que Machado de Assis criou ao ocupar a posição-de-sujeito tradutor e ao utilizar, em seu discurso sobre esse ofício, a metáfora depreciativa do escravo pode ter contribuído para construir uma identidade para os tradutores de sua época, mas uma que era melancólica. Dessa forma, Machado deixou de evidenciar, e até mesmo diminuiu, a importância da tarefa do tradutor para a sociedade como um todo e também para a literatura nacional.

O ideal cultural da época machadiana era ser um autor e não um tradutor. Era a essa posição-de-sujeito que Machado desejava se apegar. Assim, ao confundir seu papel de tradutor com o de autor, quando, por vezes, alterou o texto original ao ponto de transformá-lo em outro original, Machado deixou os tradutores sem uma referência que lhes permitisse delinear os contornos nítidos de uma identidade profissional.

Os papéis sociais assumidos pelo indivíduo, muitas vezes, deixam entrever situações interessantes, como a de um mesmo indivíduo submeter-se ao discurso mais típico de uma posição quando a ocupa e ao discurso mais típico de outra quando é essa outra a posição que está ocupando, ainda que a identidade construída por esse segundo discurso, nessa segunda posição, seja prejudicial para a construção da identidade tipicamente vinculada à posição anterior. Esse, no entanto, não é o caso de Machado de Assis, pois ainda que ora tivesse ocupado o lugar de tradutor, ora o de cronista ou crítico literário, ele sempre defendeu na prática e na teoria uma única e mesma posição: a de que o tradutor deveria, na verdade, deixar de ser escravo, servil e passivo, e assumir a identidade de autor, senhor, ativo produtor de significados.

O desejo de consolidar a nova identidade nacional e de contribuir para a formação intelectual e o enriquecimento do "pecúlio cultural" do Brasil depois da independência levou Machado de Assis a colocar o tradutor de sua época em uma posição subalterna e a lançar mão da metáfora do escravo submetido ao jugo do mercantilismo para definir esse profissional. Acredito que essa mesma imagem, com a qual não se identificava, tenha sido o fator determinante para que Machado assumisse a identidade de autor em detrimento da de tradutor. Entretanto, parece-me que Machado de Assis deve muito ao ofício que considerava inferior, um trabalho escravo, pois ele serviu de alimento para seu gênio criativo e de base para a identidade de escritor que definiu e marcou seu lugar na história da literatura brasileira.

Lourdes Sette

lourdessette@gmail.com

PUC-Rio 


\section{Referências}

ARROJO, Rosemary. As relações ambivalentes entre tradutor e teorias de tradução. Ao pé da Letra, [s.d.]. Disponível em: <http://www.revista aopedaletra.net>. Acesso em: 23-jul-2013.

BARRETTO, Eleonora. O original na tradução de Machado de Assis. In: Scientia Traductionis. Número 4, jun-2007. Disponível em: <http://www.periodicos.ufsc.br/index.php/scientia/article/view/12954/12079>.

BASNETT, Susan. Comparative Literature: a critical introduction. Oxford: Blackwell, 2003.

BELLEI, Sérgio. The Raven, by Machado de Assis. Ilha do desterro, n. 17, $1^{\circ}$ semestre 1987, pp. 47-62.

BIRMAN, Joel. Estilo e modernidade em psicanálise. São Paulo: Editora 34, 1997.

BONACIN, Larissa e SCHÄFFEL, Dicleia. Tradução poética: “O corvo” aos olhos de Machado de Assis e Fernando Pessoa. Eletras, v. 20, n. 20, pp. 222-46, 2010. Disponível em: <http://www.utp.br/eletras>. Acesso em 24-jul-2013.

CUNHA, Elaine. Da citação como tradução e crítica na obra de Machado de Assis. Disponível em <http://seer.ufrg.br/organon/article/download/ 31173/19348>. Acesso em 24-jul-2013.

FARIA, J. Roberto. Machado de Assis - tradutor de teatro. Machado de Assis em linha, Rio de Janeiro, n. 6, ano 3, pp. 48-60, dezembro de 2010. Disponível em: <http://machadodeassis.net/revista/numero06/rev_artigo 04.pdf>. Acesso em 26-jul-2013.

FERREIRA, Eliane F. Cunha. Machado de Assis: crítico e teórico do traduzir, por subtração. Em tese. v. 6, p. 21-32, agosto de 2002. Disponível em: $<$ http://www.letras.ufmg.br/poslit/08_publicacoes_pgs/

Em\%20Tese\%2006/02-Eliane.pdf >. Acesso em 23-jul-2013.

GLEDSON, John. Machado de Assis e confrades de versos. São Paulo: Minden, 1998.

LAGES, Susana Kampff. O tradutor e a melancolia. Trabalhos em Linguística Aplicada, n. 19. Campinas: Instituto de Estudos da Linguagem/Unicamp, 1992, pp. 91-98.

MAGALHÃES JÚNIOR, R. (Org.) Diálogos e reflexões de um relojoeiro. Rio de Janeiro: Civilização Brasileira, 1952.

MASSA, Jean-Michel. Machado de Assis: tradutor ou recriador. Bula revista: Literatura e Jornalismo Cultural. Disponível em: <http://acervo. revistabula.com/posts/livros/machado-de-assis-tradutor-ou-recriador $>$. Acesso em 19-06-2013.

Machado de Assis tradutor. Tradução: Oséias Silas Ferraz. Belo Horizonte: Crisálida, 2008.

ROUDINESCO, Elisabeth e PLON, Michel. Dicionário de Psicanálise. Rio de Janeiro: Zahar, 1998.

SETTE, Maria de Lourdes. A identidade (ainda melancólica?) do tradutor - uma análise desses profissionais no Brasil dos anos 90. 2002. 97 f. Dissertação (Mestrado em Estudos da Linguagem) - Programa de Pós-Graduação em Estudos da Linguagem, Pontifícia Universidade Católica do Rio de Janeiro PUC-Rio. 
92 MACHAdo TraduTOR DE Assis: A CONSTRUÇÃO DA IDENTIDADE...

SOUSA, J. Galante de. Bibliografia de Machado de Assis. Rio de Janeiro: INL-MEC, 1955.

WYLER, Lia. Línguas, poetas e bacharéis: Uma crônica da tradução no Brasil. Rio de Janeiro: Rocco, 2003. 